Bentham OPEN
CrossMark
Content list available at: $w$ ww.benthamopen.com/TOOPHTJ/

\title{
Long Term Clinical and Visual Outcomes of Retrofixated Iris Claw Lenses Implantation in Complicated Cases
}

\author{
Sri Ganesh, Sheetal Brar and Kirti Relekar \\ Nethradhama Superspeciality Eye Hospital, Bengaluru, India
}

Received: December 1, 2015

Revised: December 30, 2015

Accepted: January 19, 2016

Abstract:

Aims:

To evaluate the visual outcomes and complications after implantation of retrofixated iris claw (RFIC) lens in various challenging situations.

\section{Settings and Design:}

Retrospective, single centre, 8 year clinical audit.

\section{Materials and Methods:}

A retrospective analysis of cases who underwent RFIC lens implantation alone (group 1) or in combination with vitreoretinal (VR), corneal or glaucoma procedures (group 2) was performed. The main outcomes evaluated were corrected distant visual acuity (CDVA) and postoperative complications. The mean follow up was $13.09 \pm 6.8$ (range 6-24) months.

\section{Results:}

The study involved 100 eyes of 83 patients with mean age of $51.1 \pm 25.4$ years. Group 1 included 59 eyes and group 2 had 41 eyes. In group 1, the mean CDVA improved from $0.86 \pm 0.81$ to $0.38 \pm 0.51$ LogMAR $(p<0.001)$ with $72.8 \%$ eyes having gain in lines $(\geq 2$ lines) of CDVA with safety index of 1.73 . The mean CDVA in group 2 improved from $0.71 \pm 0.65$ to $0.38 \pm 0.34 \operatorname{LogMAR}(p=0.003$ ) with $65.8 \%$ eyes having gain in lines ( $\geq 2$ lines) of CDVA with a safety index of 1.54 . Group 2 showed a higher complication rate of $36.59 \%$ compared to group $1(20.34 \%)$. Significant complications noted were secondary glaucoma $(8 \%)$, disenclavation of haptic (4\%), subluxation of RFIC lens (1\%).

\section{Conclusion:}

The visual outcome with RFIC lenses when combined with other intraocular procedures is mainly affected by the complexity of coexisting pathologies. The complications are more related to the combined procedures performed rather than RFIC lens implantation alone. This may still be acceptable when complication profile of other intraocular lenses is evaluated in similar challenging situations.

Keywords: Combined, enclavation, intraocular lens, iris claw, retrofixated, vitreoretinal.

\section{INTRODUCTION}

The surgical correction of aphakia, crystalline lens dislocation, or dislocation of an intraocular lens (IOL) in the absence of adequate capsular support remains challenging. In these situations, an angle supported or iris supported anterior chamber intraocular lens (ACIOL), a scleral fixated posterior chamber IOL (SFIOL), a fibrin glue assisted

\footnotetext{
* Address correspondence to this author at 256/14, Kanakapura main road, $7^{\text {th }}$ block, Jayanagar, Bengaluru-560070, India; Tel: 09820516075; Fax: 26633770; E-mail: kirtirelekar@gmail.com
} 
suture less posterior chamber intraocular lens (PCIOL) - Glued IOL, or an iris fixated PCIOL have been evaluated for visual restoration [1 - 3]. However, most of these IOLs are associated with certain risks with respect to long term safety. Due to complications like corneal decompensation, cystoid macular edema (CME), secondary glaucoma, uveitis and retinal detachment $(\mathrm{RD})$, use of an ACIOL in complicated situations is not recommended [1, 2]. SFIOLs although preserve the anatomy of eye and cause less corneal endothelial damage, are technically more challenging, require more surgical time and are associated with a high incidence of complications such as lens tilting, decentration, choroidal haemorrhage, RD and CME $[1,2,4]$. Glued IOLs require the creation of scleral flaps and tucking of the IOL haptics under the flaps which can be associated with haptic related complications such as IOL decentration, haptic extrusion and subconjunctival haptic in the long term [5]. RFIC lenson the other hand, has the advantage of retropupillary posterior chamber location and a shorter learning curve [6 - 8]. Various studies done previously have mainly studied the outcome of RFIC lens implantation with aphakia being the primary indication [6]. However, they have not evaluated the outcomes of RFIC lens when combined with additional ocular surgical procedures such as vitreoretinal, corneal and glaucoma procedures. Hence this comprehensive retrospective review was conducted to analyze various indications, surgical difficulties, long term safety and visual outcomes of RFIC lens implantation when performed alone for correction of aphakia as a primary indication as well as when performed in combination with other ocular surgeries in different complicated scenarios.

\section{MATERIALS AND METHODS}

This retrospective study was approved by Institutional ethics committee and abided by the tenets of Declaration of Helsinki. The study included all patients who had undergone RFIC lens implantation with or without a combined procedure from January 2007 to December 2014. Electronic medical records of these patients were reviewed for data collection and analysis. The various combined procedures performed were (a) vitreoretinal (VR) procedures like pars plana vitrectomy (PPV), pars plana lensectomy (PPL) (b) corneal procedures like optical penetrating keratoplasty (PKP) and ACIOL explantation (c) glaucoma procedures like trabeculectomy for medically uncontrolled open angle glaucoma.

The RFIC lens used in study was OV lens (Care Group, India) which is a polymethylmethacrylate (PMMA) lens, style- ICLIP-5 with an optic size $5.0 \mathrm{~mm}$ and overall diameter of $8.5 \mathrm{~mm}$. The recommended A-constant for anterior fixation is 114.9. However, for retrofixation an A constant of 117.20 was calculated for all cases. Only cases with minimum follow up of 6 months were included. On each follow up, uncorrected distant visual acuity (UDVA), corrected distant visual acuity (CDVA), detailed anterior and posterior segment evaluation, intraocular pressure (IOP) measurements with non-contact tonometery and specular micoscopy were performed. Eligibility criteria for RFIC lens implantation were presence of healthy and sufficient iris tissue and endothelial cell count of more than $1500 \mathrm{cells} / \mathrm{mm}$.

\section{Surgical Technique:}

All procedures were performed by a single experienced surgeon (S.G.) using a standard surgical technique. All the RFIC lens implantations were combined with other procedures in the same/single setting.

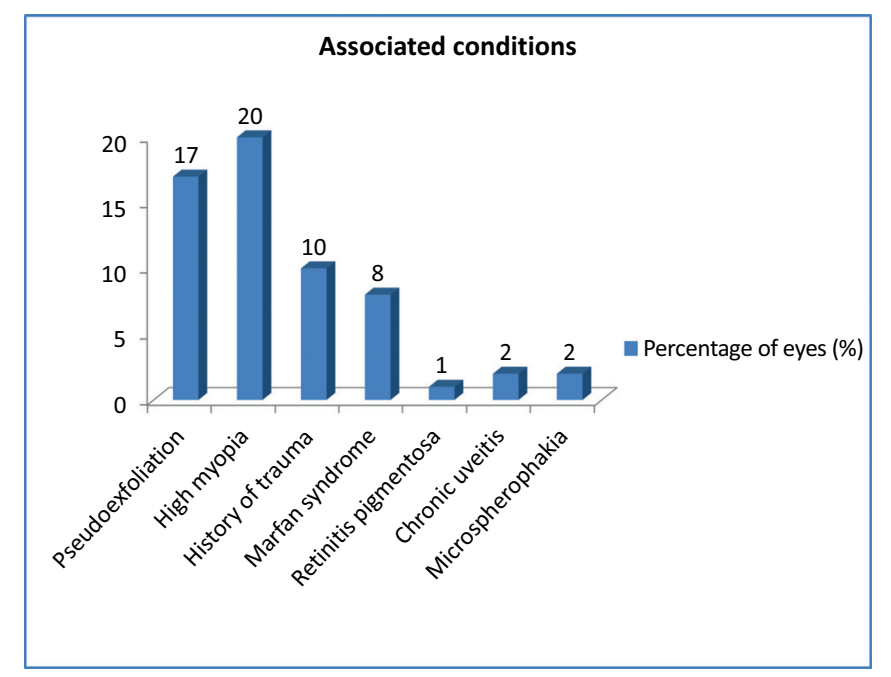

Fig. (1). Associated conditions. 
Suitable anaesthesia local/general was administered. After a conjunctival peritomy, a diamond knife was used to create a superior scleral incision $(5-5.5 \mathrm{~mm})$. The sclerocorneal tunnel was fashioned with disposable crescent blade. Two paracentesis 90 degrees from the scleral tunnel at 3 and 9 ' $\mathrm{O}$ ' clock positions were made using a $1 \mathrm{~mm}$ diamond knife. This was followed by automated anterior vitrectomy (AV) with a high cutting rate of $800 \mathrm{cpm}$ (cuts per minute), wherever indicated. Intra-cameral pilocarpine was injected for pupillary miosis. Iris claw IOL was introduced into the anterior chamber with Budo's lens holding forceps. Hypromellose 2\% (Viscomet PF, Unimed technologies) was injected at each stage to deepen the anterior chamber. Lens was aligned with the claws oriented at 3 and 9 ' $\mathrm{O}$ ' clock position. While holding the optic with the Budo's forceps, one haptic was tilted down and pushed under the iris with gentle manipulation. Simultaneously a fine tip titanium enclavation forceps was introduced through paracentesis on the same side. Once the haptic of IOL was behind iris, the haptic was tilted up to produce an indent on the iris. The iris was enclavated into the haptic claw by gentle push with the enclavation forceps. While the Budo's forceps still holding the optic, it was then gently shifted to other hand and similar manoeuvre was performed to achieve enclavation of haptic on the other side.

\section{Statistical Methods Used:}

SPSS ver. 20 (Statistical Package for Social Sciences) has been used for Statistical Analysis. All Quantitative data are analysed using paired ' $t$ ' test and for comparisons between groups Mann Whitney test is used. A probability $p$ value of $\leq 0.05$ was considered statistically significant.

\section{RESULTS}

The study included 100 eyes of 83 patients (60 males, 23 females) with mean age of $51.1 \pm 25.4$ years (range 6-94 years). 17 patients underwent bilateral implantation of RFIC lens while 66 patients had unilateral implantation of RFIC lens. The mean age of the 17 patients with bilateral RFIC lens implantation was $24 \pm 3.1$ years (range 11-35 years). The mean follow up was $13.09 \pm 6.8$ months (range 6-24 months).

\section{Indications and Associated Conditions:}

Table 1 shows the various indications for which RFIC lens implantation was performed. Surgical aphakia (due to various reasons) and subluxated clear lens formed the major indications. Fig. (1) highlights the various associated conditions found in eyes that underwent RFIC lens implantation in the study period. Sixty percent eyes were associated with significant systemic and ocular conditions mainly high myopia (20\%), pseudoexfoliation (17\%) and previous ocular trauma (10\%).

\section{Table 1. Indications.}

\begin{tabular}{|c|c|c|c|}
\hline \multicolumn{2}{|r|}{ Indication } & Number of eyes (n) & Percentage (\%) \\
\hline \multirow{3}{*}{$\begin{array}{l}\text { Secondary procedure for } \\
\text { Surgical aphakia }\end{array}$} & Post cataract surgery & 15 & 15 \\
\hline & Post lensectomy for subluxated lens & 4 & 4 \\
\hline & Post vitreo retinal surgery for retinal detachment & 3 & 3 \\
\hline \multicolumn{2}{|r|}{ Subluxated clear lens } & 21 & 21 \\
\hline \multirow{2}{*}{ Subluxated cataract } & Post trauma & 4 & 4 \\
\hline & With pseudoexfoliation & 13 & 13 \\
\hline \multicolumn{2}{|c|}{ Traumatic posterior dislocated lens } & 1 & 1 \\
\hline \multicolumn{2}{|r|}{ Subluxated IOL } & 12 & 12 \\
\hline \multicolumn{2}{|c|}{ Subluxated IOL with endocapsular ring } & 1 & 1 \\
\hline \multicolumn{2}{|r|}{ Posterior dislocated IOL } & 16 & 16 \\
\hline \multicolumn{2}{|c|}{ Primary procedure for intraoperative compromised capsular support } & 6 & 6 \\
\hline \multirow{2}{*}{ Others } & ACIOL with pseudophakic bullous keratopathy & 3 & 3 \\
\hline & Failed graft with ACIOL & 1 & 1 \\
\hline \multicolumn{2}{|r|}{ Total } & 100 & 100 \\
\hline
\end{tabular}

\section{Types of Procedures Performed:}

The various surgical procedures performed during the study period were broadly categorised into 2 groups-group 1 consisting of eyes with RFIC lens implantation performed alone and group 2 having RFIC lens implantation done with combined procedures. Group 2 was further subdivided according to the combined procedure performed along with 
RFIC lens implantation as group 2a-combined vitreoretinal, group 2b-combined penetrating keratoplasty and group 2ccombined trabeculectomy. The distribution of eyes falling in various groups is as shown in Fig. (2). Majority (59\%) of eyes had only an RFIC lens implantation while the rest had RFIC lens implantation combined with either VR (36\%), corneal $(4 \%)$ or glaucoma $(1 \%)$ procedure.

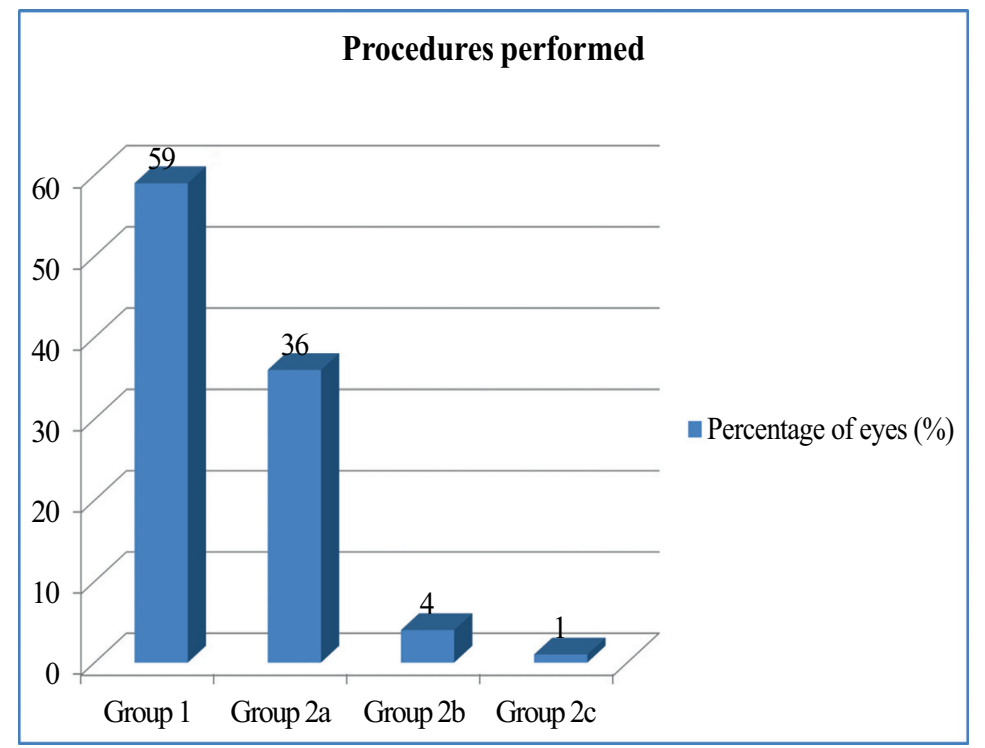

Fig. (2). Procedures performed.

Group 1-anterior segment procedure (ASP) \pm anterior vitrectomy (AV)+Retrofixated iris claw (RFIC) lens.

Group 2-combined group.

Group 2a-Vitreoretinal procedure+RFIC lens.

Group 2b-penetrating keratoplasty(PKP)+ACIOL Explantation+AV+RFIC lens.

Group 2c-ASP+AV+RFIC lens+Trabeculectomy(TRAB).

\section{Visual Outcomes:}

Table 2 and Fig. (3) show the comparison of CDVA preoperatively and postoperatively in the various groups. Group 1 and group 2 showed a significant improvement in CDVA post operatively when compared to preoperative values (probability $p$ values $<0.05$ ). The postoperative refractive errors were within \pm 2.25 diopter (D) of emmetropia in $95 \%$ of eyes. A high safety index was observed being 1.73 for group 1 and 1.54 for group 2 . In group 1, 72.8\% of eyes had gain in lines ( $\geq 2$ lines) of CDVA while $3.38 \%$ of eyes had loss of lines ( $\leq 3$ lines) of CDVA. In group 2 , gain in lines of CDVA was observed in $65.8 \%$ of eyes while $17.07 \%$ of eyes had loss of lines of CDVA.

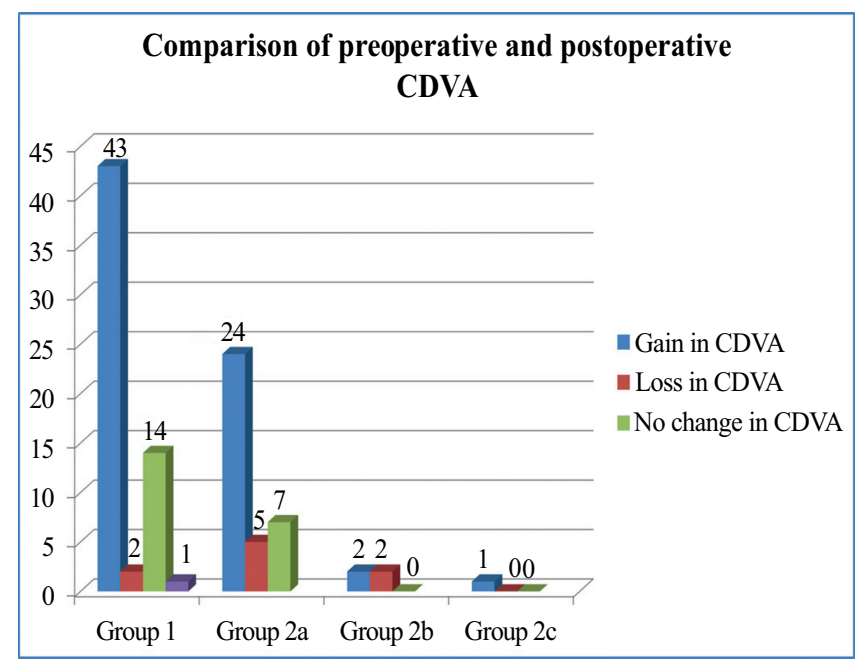

Fig. (3). Comparison of preoperative and postoperative corrected distant visual acuity (CDVA). 


\section{Complications:}

Of the total 100 eyes, 27 eyes showed various complications at the end of mean follow up, mainly secondary glaucoma and corneal decompensation. Details of complications in various study groups are provided in Table 3. Group 1 had a complication rate of $20.34 \%$ (12/59 eyes) while group 2 showed a comparatively higher complication rate of $36.59 \%$ ( $15 / 41$ eyes). 5 eyes required repeat surgical intervention- 4 eyes for disenclavated haptic and 1 eye for subluxated RFIC lens. Slight pupillary ovalization was seen in $34 \%$ of eyes.

The mean endothelial cell count was $1852.73 \pm 104.49$ cells $/ \mathrm{mm}^{2}$ at 6 months postoperatively with an endothelial cell loss of $10.74 \%$.

Table 2. Comparison of corrected distant visual acuity (CDVA) preoperatively and postoperatively in logMAR in Group 1 and Group 2.

\begin{tabular}{|l|c|c|c|c|}
\hline & Pre operative CDVA (mean \pm SD) & Post operative CDVA(mean \pm SD) & $p$ value & Safety Index \\
\hline Group 1 $(\mathrm{n}=59)$ & $0.867 \pm 0.813$ & $0.384 \pm 0.515$ & $<0.001$ & 1.73 \\
\hline Group 2 $(\mathrm{n}=41)$ & $0.715 \pm 0.656$ & $0.384 \pm 0.346$ & 0.003 & 1.54 \\
\hline
\end{tabular}

Mann Whitney U Value Test

\section{DISCUSSION}

ACIOLs and SFIOLs are commonly performed surgical options for management of aphakia in the absence of adequate capsular support and have long been evaluated [7, 8]. With the advent of iris fixated IOL, many lacunae of ACIOLs and SFIOLs such as involvement of angle structures and transcleral fixation were overcome. The midperipheral iris stromal fixation of iris fixated IOL is advantageous as the midperipheral iris stroma is virtually immobile, less vascularised and less reactive. Further with retropupillary fixation, the risk of corneal decompensation is reduced by virtue of its posterior chamber location. Also, they do not affect mydriasis or interfere with angle structures $[9,10]$.

In the present study, we observed better outcomes when RFIC lens implantation was performed alone, compared to when performed in combination with other intraocular procedures. This was evident by improvement in CDVA in $73 \%$ of eyes by $\geq 2$ lines. A number of studies have shown similar good visual outcomes with implantation of RFIC lens when performed alone as primary or secondary procedure for management of aphakia with a favourable complication rate [11 - 15].

Table 3. Complications.

\begin{tabular}{|c|c|c|c|c|c|}
\hline Complications & Group 1 (n=59) & Group 2a(n=36) & Group 2b (n=4) & Group 2c (n=1) & Total \\
\hline Secondary glaucoma & 2 & 5 & 1 & 0 & 8 \\
\hline Corneal decompensation & 4 & 1 & 0 & 0 & 5 \\
\hline Cystoid macular oedema & 2 & 3 & 0 & 0 & 5 \\
\hline Haptic disenclavation & 2 & 2 & 0 & 0 & 4 \\
\hline Subluxated retrofixated iris claw lens & 0 & 1 & 0 & 0 & 1 \\
\hline Persistent uveitis & 1 & 0 & 0 & 0 & 1 \\
\hline Retinal detachment & 1 & 0 & 0 & 0 & 2 \\
\hline Graft failure & 0 & 0 & 2 & 0 & 27 \\
\hline Total & 12 & 12 & 3 & & 0 \\
\hline
\end{tabular}

Major complications noted in our study were corneal decompensation (6.7\%), secondary glaucoma (3.38\%), haptic disenclavation (3.38\%) and CME (3.38\%). We observed a lower incidence of haptic disenclavation in group 1 compared to other studies (range $6-8.7 \%$ ) $[6,11,12]$. This may be due to meticulous surgical technique and surgeons expertise. We did not have any case of endophthalmitis or toxic anterior segment syndrome as observed in other studies [11]. However, we observed secondary glaucoma in contrast to other studies which was managed successfully with topical antiglaucoma medications [10,11].

We observed a good visual outcome when RFIC lens implantation was combined with vitreoretinal procedures, with $66.7 \%$ eyes showing a gain of $\geq 2$ lines in CDVA postoperatively. However, 5 eyes lost $\leq 3$ lines in CDVA due to CME (8.3\%) and corneal decompensation (2.7\%). Compared to the study by Pattnaik et al., our incidence of secondary glaucoma in this group was lower (13.8\%) and we did not observe any case of vitreous haemorrhage [16]. Incidence of resurgery due to subluxation or haptic disenclavation in this group was $8.3 \%$ when compared to that observed by 
Ramon et al. (15.6\%) [18]. In all such cases who underwent resurgery, the RFIC lens remained stable until the last follow up and the visual outcomes were not affected. Previous studies have evaluated the safety and efficacy of RFIC lens in patients requiring concomitant vitreoretinal procedures and have shown favourable results [16 - 24].

In our study, 4 eyes underwent combined penetrating keratoplasty, ACIOL explantation and RFIC lens implantation for bullous keratopathy secondary to ACIOL. Visual acuity improved from counting finger at 1 meter to 6/24 in 2 eyes. However, 2 eyes did not show improvement in visual acuity due to subsequent graft failure. Previous studies have shown good visual results and favourable complication rate with RFIC lens implantation combined with PKP for various indications [25 - 27]. The most common indication for combining PKP with RFIC lens in previous studies was also pseudophakic bullous keratopathy $[25,26]$.

One patient in this series had secondary elevation of IOP, which was medically controlled and did not lead to graft failure. In a series of 12 eyes combining PKP+ RFIC lens implantation by Rufer et al. the most frequent complication encountered was postoperative glaucoma [27]. However, Gonnermann et al. did not observe any significant change in IOP in their study [26].

Studies combining PKP with SFIOL have also demonstrated good clinical outcome [26 - 28]. However, certain complications such as vitreous haemorrhage, postoperative endophthalmitis and partial IOL dislocation have been reported. Vitreous haemorrhage due to trauma to ciliary body and root of iris may occur at the time of surgery or in immediate postoperative period. Exposure of scleral suture may increase the risk of endophthalmitis [28 - 30]. Unequal placement or tying of scleral fixation suture may lead to partial IOL dislocation requiring refixation [28, 31]. RFIC lens may be safer in this scenario as most of the suture related complications [32]. associated with SFIOLs can be avoided improving long term safety.

Moreover, ultrasound biomicroscopy studies on eyes with combined PKP with RFIC lens have shown that enclavation to the posterior plane of iris preserves the anatomy of the anterior segment with respect to the iridocorneal angle [25, 33]. This may also be relevant in eyes requiring combined trabeculectomy and RFIC lens implantation. In our series, we had only one such eye that underwent combined trabeculectomy with Mitomycin C and RFIC lens implantation for a grossly subluxated cataract with pseudoexfoliation glaucoma. The postoperative outcomes were good with improvement in CDVA from counting finger 2 meter to 6/7.5.

Literature does not report outcomes of combined glaucoma filtration surgery simultaneously with RFIC lens implantation. However, one case undergoing RFIC lens implantation following traumatic wound dehiscence of trabeculectomy scleral flap has been reported [34]. Theoretically, RFIC lens would be a better option compared to SFIOL and glued IOL in glaucomatous eyes due to advantages of being sutureless, preservation of trabecular meshwork structures and avoidance of creation of additional scleral flaps, thus ensuring long term safety and structural integrity of the eye.

To the best of our knowledge, this is the first study evaluating the outcome of RFIC lens implantation in different challenging cases in a long term ( 8 years) retrospective clinical audit. The results support the superiority of retrofixated iris claw IOL over other modalities (SFIOL, glued IOL) in similar situations. However, we observed a comparatively higher complication rate $(36.59 \%)$ when RFIC lens implantation was combined with additional intraocular procedures (pars plana vitrectomy, penetrating keratoplasty, trabeculectomy) compared to when performed alone (20.34\%). This is anticipated, since by combining two intraocular procedures, the overall risk of complications is expected to increase. This may also explain the comparatively higher percentage of eyes with loss of best corrected visual acuity in the combined group. Nevertheless, the long term visual outcomes were satisfactory with good safety profile and with overall low risk of serious and sight threatening complications.

\section{CONFLICT OF INTEREST}

The authors confirm that this article content has no conflict of interest.

\section{ACKNOWLEDGEMENTS}

Declared none.

\section{REFERENCES}

[1] Dick HB, Augustin AJ. Lens implant selection with absence of capsular support. Curr Opin Ophthalmol 2001; 12(1): 47-57. [http://dx.doi.org/10.1097/00055735-200102000-00009] [PMID: 11150081] 
[2] Wagoner MD, Cox TA, Ariyasu RG, Jacobs DS, Karp CL. Intraocular lens implantation in the absence of capsular support: a report by the American Academy of Ophthalmology. Ophthalmology 2003; 110(4): 840-59. [http://dx.doi.org/10.1016/S0161-6420(02)02000-6] [PMID: 12689913]

[3] Agarwal A, Kumar DA, Jacob S, Baid C, Agarwal A, Srinivasan S. Fibrin glue-assisted sutureless posterior chamber intraocular lens implantation in eyes with deficient posterior capsules. J Cataract Refract Surg 2008; 34(9): 1433-8. [http://dx.doi.org/10.1016/j.jcrs.2008.04.040] [PMID: 18721701]

[4] Dadeya S, Kamlesh K, Kumari SP. Secondary intraocular lens (IOL) implantation: anterior chamber versus scleral fixation long-term comparative evaluation. Eur J Ophthalmol 2003; 13(7): 627-33.

[PMID: 14552597]

[5] Kumar DA, Agarwal A, Packiyalakshmi S, Jacob S, Agarwal A. Complications and visual outcomes after glued foldable intraocular lens implantation in eyes with inadequate capsules. J Cataract Refract Surg 2013; 39(8): 1211-8. [http://dx.doi.org/10.1016/j.jcrs.2013.03.004] [PMID: 23726133]

[6] Mohr A, Hengerer F, Eckardt C. Retropupillary fixation of the iris claw lens in aphakia. 1 year outcome of a new implantation techniques. Ophthalmologe 2002; 99(7): 580-3.

[http://dx.doi.org/10.1007/s00347-001-0563-z] [PMID: 12148307]

[7] Menezo JL, Martinez MC, Cisneros AL. Iris-fixated Worst claw versus sulcus-fixated posterior chamber lenses in the absence of capsular support. J Cataract Refract Surg 1996; 22(10): 1476-84.

[http://dx.doi.org/10.1016/S0886-3350(96)80151-9] [PMID: 9051506]

[8] Hsing YE, Lee GA. Retropupillary iris claw intraocular lens for aphakia. Clin Experiment Ophthalmol 2012; 40(9): 849-54. [http://dx.doi.org/10.1111/j.1442-9071.2012.02808.x] [PMID: 22594520]

[9] Güell JL, Velasco F, Malecaze F, Vázquez M, Gris O, Manero F. Secondary Artisan-Verysise aphakic lens implantation. J Cataract Refract Surg 2005; 31(12): 2266-71. [http://dx.doi.org/10.1016/j.jcrs.2005.06.047] [PMID: 16473216]

[10] Baykara M, Ozcetin H, Yilmaz S, Timuçin OB. Posterior iris fixation of the iris-claw intraocular lens implantation through a scleral tunnel incision. Am J Ophthalmol 2007; 144(4): 586-91. [http://dx.doi.org/10.1016/j.ajo.2007.06.009] [PMID: 17692274]

[11] Gonnermann J, Klamann MK, Maier AK, et al. Visual outcome and complications after posterior iris-claw aphakic intraocular lens implantation. J Cataract Refract Surg 2012; 38(12): 2139-43.

[http://dx.doi.org/10.1016/j.jcrs.2012.07.035] [PMID: 23036355]

[12] De Silva SR, Arun K, Anandan M, Glover N, Patel CK, Rosen P. Iris-claw intraocular lenses to correct aphakia in the absence of capsule support. J Cataract Refract Surg 2011; 37(9): 1667-72. [http://dx.doi.org/10.1016/j.jcrs.2011.03.051] [PMID: 21855764]

[13] Rao R, Sasidharan A. Iris claw intraocular lens: a viable option in monocular surgical aphakia. Indian J Ophthalmol 2013; 61(2): 74-5. [http://dx.doi.org/10.4103/0301-4738.107198] [PMID: 23412525]

[14] Lett KS, Chaudhuri PR. Visual outcomes following Artisan aphakia iris claw lens implantation. Eye (Lond) 2011; 25(1): 73-6. [http://dx.doi.org/10.1038/eye.2010.146] [PMID: 20948556]

[15] Gonnermann J, Torun N, Klamann MK, et al. Posterior iris-claw aphakic intraocular lens implantation in children. Am J Ophthalmol 2013; 156(2): 382-386.e1. [http://dx.doi.org/10.1016/j.ajo.2013.03.002] [PMID: 23721944]

[16] Pattnaik L, Almozawak K, Binder S. Pars plana vitrectomy and artisan iris fixated intraocular lens for aphakia in complicated vitreoretinal referrals. J Acute Dis 2013; 2(2): 109-14. [http://dx.doi.org/10.1016/S2221-6189(13)60109-2]

[17] Patil KB, Meleth P, Shanker MP. Pars plana vitrectomy with posterior iris claw implantation for posteriorly dislocated nucleus and intraocular lens. Indian J Ophthalmol 2011; 59(6): 497-500. [http://dx.doi.org/10.4103/0301-4738.86321] [PMID: 22011497]

[18] Anglada R, Castellví J, Parera A, Sabala A. Inverted implantation of posterior iris-fixated intraocular lens with 23G transconjunctival vitrectomy in the management of secondary implant-Technique and stability, astigmatism and endothelial loss outcomes. J Emmetropia 2014; 5(3): 133-43.

[19] Kodjikian L, Beby F, Spire M, et al. Combined pars plana phacofragmentation, vitrectomy, and Artisan lens implantation for traumatic subluxated cataracts. Retina 2006; 26(8): 909-16.

[http://dx.doi.org/10.1097/01.iae.0000250005.38037.da] [PMID: 17031292]

[20] van der Meulen IJ, Gunning FP, Vermeulen MG, de Smet MD. Artisan lens implantation to correct aphakia after vitrectomy for retained nuclear lens fragments. J Cataract Refract Surg 2004; 30(12): 2585-9. [http://dx.doi.org/10.1016/j.jcrs.2004.04.050] [PMID: 15617928]

[21] Riazi M, Moghimi S, Najmi Z, Ghaffari R. Secondary Artisan-Verysise intraocular lens implantation for aphakic correction in post-traumatic vitrectomized eye. Eye (Lond) 2008; 22(11): 1419-24. [http://dx.doi.org/10.1038/eye.2008.271] [PMID: 18756286] 
[22] Acar N, Kapran Z, Altan T, Kucuksumer Y, Unver YB, Polat E. Secondary iris claw intraocular lens implantation for the correction of aphakia after pars plana vitrectomy. Retina 2010; 30(1): 131-9. [http://dx.doi.org/10.1097/IAE.0b013e3181b32eef] [PMID: 19834354]

[23] Català-Mora J, Díaz-Cascajosa J, Ferreruela-Sanfeliu G, Castany-Aregall M, Prat-Bartomeu J, García-Arumí J. 23-G pars plana vitrectomy, lensectomy, and artisan IOL implantation for the management of nontraumatic ectopia lentis: a new iris enclavation technique for iris claw lens. Retina 2012; 32(6): 1214-6. [http://dx.doi.org/10.1097/IAE.0b013e31824d4f06] [PMID: 22643806]

[24] Farrahi F, Feghhi M, Haghi F, Kasiri A, Afkari A, Latifi M. Iris claw versus scleral fixation intraocular lens implantation during pars plana vitrectomy. J Ophthalmic Vis Res 2012; 7(2): 118-24. [PMID: 23275819]

[25] Dighiero P, Guigou S, Mercie M, Briat B, Ellies P, Gicquel JJ. Penetrating keratoplasty combined with posterior Artisan iris-fixated intraocular lens implantation. Acta Ophthalmol Scand 2006; 84(2): 197-200. [http://dx.doi.org/10.1111/j.1600-0420.2005.00573.x] [PMID: 16637836]

[26] Gonnermann J, Torun N, Klamann MK, et al. Visual outcomes and complications following posterior iris-claw aphakic intraocular lens implantation combined with penetrating keratoplasty. Graefes Arch Clin Exp Ophthalmol 2013; 251(4): 1151-6. [http://dx.doi.org/10.1007/s00417-012-2226-y] [PMID: 23250481]

[27] Rüfer F, Saeger M, Nölle B, Roider J. Implantation of retropupillar iris claw lenses with and without combined penetrating keratoplasty. Graefes Arch Clin Exp Ophthalmol 2009; 247(4): 457-62. [http://dx.doi.org/10.1007/s00417-008-0940-2] [PMID: 18787833]

[28] Koçak-Altintas AG, Koçak-Midillioglu I, Dengisik F, Duman S. Implantation of scleral-sutured posterior chamber intraocular lenses during penetrating keratoplasty. J Refract Surg 2000; 16(4): 456-8. [PMID: 10939726]

[29] Davis RM, Best D, Gilbert GE. Comparison of intraocular lens fixation techniques performed during penetrating keratoplasty. Am J Ophthalmol 1991; 111(6): 743-9. [http://dx.doi.org/10.1016/S0002-9394(14)76783-2] [PMID: 2039047]

[30] Soong HK, Musch DC, Kowal V, Sugar A, Meyer RF. Implantation of posterior chamber intraocular lenses in the absence of lens capsule during penetrating keratoplasty. Arch Ophthalmol 1989; 107(5): 660-5. [http://dx.doi.org/10.1001/archopht.1989.01070010678026] [PMID: 2655567]

[31] Schein OD, Kenyon KR, Steinert RF, et al. A randomized trial of intraocular lens fixation techniques with penetrating keratoplasty. Ophthalmology 1993; 100(10): 1437-43.

[http://dx.doi.org/10.1016/S0161-6420(93)31458-2] [PMID: 8414402]

[32] Price MO, Price FW Jr, Werner L, Berlie C, Mamalis N. Late dislocation of scleral-sutured posterior chamber intraocular lenses. J Cataract Refract Surg 2005; 31(7): 1320-6. [http://dx.doi.org/10.1016/j.jcrs.2004.12.060] [PMID: 16105601]

[33] Gicquel JJ, Guigou S, Bejjani RA, Briat B, Ellies P, Dighiero P. Ultrasound biomicroscopy study of the Verisyse aphakic intraocular lens combined with penetrating keratoplasty in pseudophakic bullous keratopathy. J Cataract Refract Surg 2007; 33(3): 455-64. [http://dx.doi.org/10.1016/j.jcrs.2006.11.017] [PMID: 17321397]

[34] Rubinstein A, Salmon JF. Late traumatic scleral flap dehiscence following trabeculectomy. Eye (Lond) 2007; 21(1): 145-6. [http://dx.doi.org/10.1038/sj.eye.6702476] [PMID: 16763651]

(C) Ganesh et al.; Licensee Bentham Open.

This is an open access article licensed under the terms of the Creative Commons Attribution-Non-Commercial 4.0 International Public License (CC BY-NC 4.0) (https://creativecommons.org/licenses/by-nc/4.0/legalcode), which permits unrestricted, non-commercial use, distribution and reproduction in any medium, provided the work is properly cited. 